\section{Transient binasal hemianopia in a pair of plastic soupspoons*}

\author{
HERBER'T F. CROVITZ \\ Veterans Administration Hospital, Durham, N.C. 27705
}

When color rivalry is studied at short tachistoscopic exposures, split color fields are often reported in which the target space appears to contain the two colors in some spatial arrangement. A split field in which the nasal visual field color is suppressed within the target space is sometimes reported, using small rivalrous targets. The present study examines this transient color rivalry in the limit of target area, using a simple Ganzfeld method.

Köllner (1914) held different color filters before his closed eyes and found that the first fleeting perception upon opening his eyes and viewing a white surface through the rivalrous filters was a split field of color. The color before the left eye was seen to the left of the fixation point and the color before the right eye was seen to the right of the fixation point. He wrote that the suppression of the nasal visual fields lasted a short time, followed by the ordinary flow of color rivalry, and required the viewing of a large white field of at least $50 \mathrm{deg}$ of visual angle.

Rich (1964) and Lipscomb (1965) found that Köllner's effect grew in likelihood as there was an increase in size of the retinal area subtended, using a controlled tachistoscopic exposure of $100 \mathrm{msec}$. For example, in the study of Rich, with 1-, 2-, 4-, and 7 -deg rivalrous targets, the relative proportion of all trials that gave a report of a split field with the left-eye color to the left of the right-eye color within the target space was, respectively, $10.4 \%, 4.9 \%, 15.0 \%$, and $39.5 \%$. In the study of Lipscomb, a similar increase was found. Crovitz \& Lipscomb (1963) had 16 Os view a $100-\mathrm{msec}$ flash of rivalrous colored rectangles subtending 10 deg vertically and $13 \mathrm{deg}$ horizontally, finding that in 20 such flashes per $0,46.9 \%$ of the reported percepts were of the left-eye color to the left of the right-eye color within the target space.

The goal of the present study was to carry target size to the limit, inquiring about the probability of the Köllner effect in a tachistoscopic Ganzfeld.

\section{METHOD}

The convex surface of "Banquet" plastic soup spoons (Van Brode Milling Company) was painted with green or red glass stain (Cunningham Art Products, SG 328 , Kelly green, and

*Parts of this paper were delivered at the 12th Annual Meetirgs of the Psychonomic Society, St. Louis, November 13, 1971. insure that each spoon transmitted light of approximately equal brightness.

There were two experiments. In both, Duke undergraduates with normal color vision held the spoons by their handles snugly over their open eyes, with instructions to fixate straight ahead. To limit the effects of color adaptation, the spoons were held with red and green over opposite eyes on successive trials. Following each flash, $\mathrm{S}$ was asked to describe the spatial arrangement of whatever colors he had seen.

In Experiment 1, 19 Ss were given six trials each. The spoons on the eyes were $12 \mathrm{in.}$. in front of a curved paper diffusing screen, $7 \mathrm{in}$. behind which was a photoflash gun (Kako-77) which delivered a flash of about $1 \mathrm{msec}$ in duration.

In Experiment 2, nine Ss were given 20 trials each. The spoons were held over the eyes with the head held close of a three-channel tachistoscope (Scientific Prototype Model GB). Exposure duration of the light falling on the spoons was 50 msec.

\section{RESULTS}

In both experiments, all Ss reported the left-eye color to the left of the right-eye color on most trials. However, there was a scattering of other percepts reported. The Kölner effect consists of equal areas of the two colors, the left-eye color to the left of the right-eye color. An unequal Köllner effect was sometimes reported with the dividing line between the
SG 301, red), using paint thinner to to the center of the open field, No. 2, colors to one side of the midline. As in previous experiments, yet other percepts were reported, though infrequently. These were stripes (in which one eye's color was perceived in the center of the visual field, with the other eye's color flanking it on both sides), a reversed Köllner effect (in which the left-eye color was seen to the right of the right-eye color), and full monocular dominance (in which the color flashed to one eye was seen throughout the visual field).

Table 1 shows the percentage of all trials on which each of these percepts was reported in the two experiments.

\section{DISCUSSION}

In the present experiments, using rivalrous Ganzfelds, there was a high probability of suppression of the nasal visual fields. This is particularly interesting in the case of Experiment 2. The nine $S$ s in that experiment were specially selected from a pool of college students who had a history of squint in childhood, who now had larger phorias than the Ss in Experiment 1, and who tended to suppress vision in one eye when illumination was continuous. These results invite studies to determine the extent to which transient binasal hemianopia precedes the steady-state suppression of the view of one eye in Ss with abnormal binocular vision, as it precedes the flow of rivalry for normal observers.

\section{REFERENCES}

CROVITZ, H. F., \& LIPSCOMB, D. B. Dominance of the temporal visual fields at a short duration of stimulation. The American Journal of Psychology, 1963, 76, 631-637.

KÖLLNER, H. Das funktionelle Überwiegen der nasalen Netzhauthälten in gemeinschaftlichen Sehfeld. Archiv für Augenheilkunde, 1914, 76, 153-164.

LIPSCOMB, D. B. A comparative study of phenomenal suppression patterns in the tachistoscopic binocular rivalry of chromatic, achromatic, and contour stimuli. Unpublished doctoral dissertation, Duke University, 1965.

RICH, E. B. Changes in the Köllner effect as a function of stimulus-size. Unpublished master's thesis, Duke University, 1964.

Table 1

Percentage of Reports in the Two Experiments

\begin{tabular}{|c|c|c|c|c|c|}
\hline & \multicolumn{3}{|c|}{ Köllner Effect } & \multirow[b]{2}{*}{ Stripes } & \multirow{2}{*}{$\begin{array}{c}\text { Full } \\
\text { Monocular } \\
\text { Dominance }\end{array}$} \\
\hline & Equal & Unequal & Reversed & & \\
\hline Experiment 1 & 73.7 & 20.2 & 0 & 3.5 & 2.6 \\
\hline Experiment 2 & 82.8 & 7.8 & 2.7 & 6.7 & 0 \\
\hline
\end{tabular}

